\title{
Pancreatic $\beta$-cells expressing GLP-1 are resistant to the toxic effects of immunosuppressive drugs
}

\author{
Eugenio D’Amico ${ }^{1,2}$, Hongxiang Hui ${ }^{1,3}$, Nasif Khoury', Umberto Di Mario ${ }^{4}$ and \\ Riccardo Perfetti ${ }^{1,3}$ \\ ${ }^{1}$ Division of Endocrinology, Cedars-Sinai Medical Center, Los Angeles, California, USA \\ 'Universita' 'Magna Graecia', Catanzaro, Italy \\ ${ }^{3}$ University of California, Los Angeles, California, USA \\ ${ }^{4}$ Department of Clinical Sciences, University 'La Sapienza', Rome, Italy
}

(Requests for offprints should be addressed to R Perfetti; Email: perfettir@cshs.org)

\begin{abstract}
Glucose intolerance is often observed after pancreatic islet cell transplantation. The administration of immunosuppressive agents (ISD), necessary to avoid tissue rejection, is in part responsible for hyperglycemia. To investigate whether mouse insulinoma (MIN6) cells transfected with the glucagon like peptide-1 (GLP-1) fragment of the proglucagon gene (RIP/GLP-1 MIN6 cells) are resistant to the toxicity derived from the administration of ISD. RIP/GLP-1 MIN6 cells, as well as parental MIN6 cells, were exposed to a cocktail of ISD. The secretion of insulin and the expression of apoptosis-related proteins were investigated by RIA and western blot analysis. Cell apoptosis was quantified by FACS analysis. Finally, to study whether the antiapoptotic action of GLP-1 was a function of its effect on insulin secretion, or rather it was a direct effect of GLP-1, cells were cultured with or without diazoxide or exendin-9. GLP-1 improved the functional activity and the viability of cells exposed to ISD. The insulin secretion of RIP/GLP-1 MIN6 cells after exposure to ISD was preserved. The expression of GLP-1 by $\beta$-cells reduced the number of apoptotic cells and increased the expression of the antiapoptotic protein Bcl-2. GLP-1 also decreased the abundance of the proapoptotic markers PARP-p85 and Smac/Diablo. Treatment of cells with the diazoxide did not abolish the protective advantage that cells transfected with GLP-1 had; conversely the exposure of cells to exendin- 9 was associated with a restored susceptibility to apoptosis. This report demonstrates that GLP-1 is capable of preserving $\beta$-cell function and protecting cells from apoptotic cell death.
\end{abstract}

Journal of Molecular Endocrinology (2005) 34, 377-390

\section{Introduction}

The control of plasma glucose levels has been recognized to be a major determinant in preventing and/or delaying the onset of complications in patients with diabetes (Lakey et al. 1999). Equally well established is the observation that maintaining normal blood glucose concentrations is often quite a difficult goal to reach. The transplantation of pancreatic tissue, either the whole organ or purified pancreatic islets, has led to a renewed interest in transplantation as a treatment for diabetes mellitus (The Diabetes Control and Complications Trial Research Group 1998, Drachenberg et al. 1999). With the increase in the availability of new and more potent immunosuppressive drugs, different strategies have been proposed specifically for islet transplantation. Shapiro et al. (2000) have developed a glucocorticoid-free immunosuppressive protocol that includes sirolimus, low-dose tacrolimus, and a monoclonal antibody against the interleukin-2 receptor (daclizumab) for islet transplantation in patients with brittle type 1 diabetes. The addition of mycophenolate mofetil to immunosuppressive regimens has been shown to reduce even further the incidence of rejection following pancreas or islets transplantation (Sato et al. 2003).

A recent review of the potential barriers to insulin independence after islet transplantation identified several factors (Hering \& Ricordi 1999). The number of $\beta$-cells may be inadequate owing to insufficient engraftment of islets and immediate cellular loss through apoptosis and other non-immune-mediated inflammatory pathways (Bennet et al. 1999). A persistent impairment of glucose metabolism after transplantation has been attributed to various causes, including impaired insulin secretion (Patty et al. 2002) and $\beta$-cells apoptosis induced by the administration of immunosuppressive drugs (ISD) (Drachenberg et al. 1999).

For any type of immunossuppression after transplantation, a balance is sought between efficacy and toxicity. A major advance toward achieving insulin independence following islet transplantation or pancreas 
transplantation is to eliminate, or minimize, the use of immunosuppressive agents known to have $\beta$-cell toxicity (Zeng et al. 1993) or to induce peripheral insulin resistance (Sutherland et al. 2001). An alternative strategy might consider ways to enhance the resistance of islets to the toxic effects of ISD.

Recent reports have shown that the gastrointestinal hormone glucagon-like peptide 1 (GLP-1), in addition to regulating the secretion of insulin and the expression of islet-specific genes (Hussain \& Habener 2000, Drucker 2003), has significant antiapoptotic properties. In diabetic ZDF rats, as well as in streptozotocin-induced diabetic mice, treatment with GLP-1 or exendin-4 (a long-acting analog of GLP-1) protects $\beta$-cells from apoptosis (Farilla et al. 2002, Li et al. 2003). In vitro studies using insulin-secreting cells (Hui et al. 2002) or fibroblast-expressing GLP-1 receptors (Li et al. 2003) have shown that the protective action of GLP-1 is not an indirect effect resulting from the normalization of the ambient glucose levels, but rather it has a direct effect on cell viability and is mediated by an increase inexpression of antiapoptotic proteins and down-regulation of proapoptotic proteins (Farilla et al. 2002, Hui et al. 2003, Li et al. 2003).

The aim of this study was to investigate whether GLP-1 would confer resistance to the toxic effects of ISD, preserving the viability and function of $\beta$-cells. Using our previously described $\beta$-cell line transfected with the GLP-1 fragment of the human proglucagon gene (Hui et al. 2002), we demonstrate that GLP-1 counteracts the negative effects of ISD, improving the glucose-dependent capability to secrete insulin and reducing $\beta$-cell death.

\section{Materials and methods}

\section{Cell culture}

Mouse insulinoma (MIN-6) cells were a gift from Dr Junichi Miyazaki (Kumamoto University; Kumamoto, Japan). Transfection of MIN6 cells with the GLP-1 fragment of the human proglucagon gene, under the control of the rat insulin II promoter (RIP/GLP-1 construct) has been previously described by Hui et al. (2002). RIP/GLP-1 MIN6 cells have been shown to be capable of promoting the synthesis and secretion of GLP-1 and insulin in a glucose-dependent manner. Cells were cultured in Dulbecco's modified Eagle's medium (DMEM) medium (Life Technologies Inc., Gaithersburg, MD, USA) containing $100 \mu \mathrm{g} / \mathrm{ml}$ penicillin, $50 \mu \mathrm{g} / \mathrm{ml}$ streptomycin, and $10 \%$ fetal bovine serum (FBS) (Gemini Bio-Products Inc., Woodland, GA, USA) at $37{ }^{\circ} \mathrm{C}$ under a humidified condition of $95 \%$ air and $5 \% \mathrm{CO} 2$. All cell culture studies were conducted using cells grown to $80 \%$ confluence and exposed for $48 \mathrm{~h}$ to medium containing a cocktail of ISD, or an equivalent volume of the medium used to dilute each of the drugs used. The ISD used included sirolimus (Rapamycin, Sigma Aldrich, St Louis, MO, USA) at concentrations of $25 \mathrm{ng} / \mathrm{ml}$; mycophenolate, (Mycophenolic acid, Calbiochem, La Jolla, CA, USA) at concentrations of 17.5 ug/ml; and tacrolimus (Prograf, Fujisawa, Deerfield, NJ, USA) at concentrations of $75 \mathrm{ng} / \mathrm{ml}$. Drug dilutions were made from fresh stock before each experiment. Sirolimus was solubilized in dimethyl sulfoxide, mycophenolate in $70 \%$ ethanol, and tacrolimus in sterile water. The selection of those agents was based on the protocol for immunosuppression often employed after pancreatic islets transplantation (Shapiro et al. 2000), and the concentrations of ISD used in the present study were selected on the basis of previous experiments performed in our laboratory (Hui et al. 2004).

In some studies, human recombinant GLP-1 (American Peptide Company; Sunnyvale, CA, USA) was added to the culture medium of parental MIN6 cells. Those experiments were aimed at investigating whether the effect of ISD on RIP/GLP-1 MIN6 cells was specifically due to their capability of producing GLP-1, or whether it was the effect of a clonal selection resulting from the process of cell transfection. Cells were evaluated for insulin secretion, viability, and the expression of anti-apoptotic and pro-apoptotic factors. The specific culture conditions for each individual experiment are detailed in the specific experimental protocol described hereafter. All experiments with transfected MIN6 cells were performed using pools of stably transfected clones.

\section{Measurement of insulin secretion}

Parental MIN6 and RIP/GLP-1 MIN-6 cells were plated at a density of $1 \times 10^{6}$ cells/well in 6 -wells plates. After they reached confluence, cells were subjected to a $2 \mathrm{~h}$ wash-out and cultured in serum-free medium containing $25 \mathrm{mM}$ glucose and a cocktail of ISD (sirolimus $(25 \mathrm{ng} / \mathrm{ml})$, mycophenolate $(17.5 \mathrm{ug} / \mathrm{ml})$ and tacrolimus $(75 \mathrm{ng} / \mathrm{ml})$ ) for $48 \mathrm{~h}$. Control cultures were incubated in the absence of ISD for the same length of time. After a $48 \mathrm{~h}$ treatment the cells were subjected to a $2 \mathrm{~h}$ wash-out period in serum-free/glucose-free medium, and exposed for $1 \mathrm{~h}$ to medium containing either $5 \cdot 6$ or $16.7 \mathrm{mM}$ glucose. The level of insulin in the culture medium was measured by RIA (Linco Research Inc., St Charles, MA, USA) and normalized for the total cellular protein content detected in the pellet of each individual culture, as measured using the Bradford method (Bio-Rad Laboratories Inc., Richmond, CA, USA).

\section{LIVE/DEAD viability/cytotoxicity}

Parental and RIP/GLP-1 MIN6 cells were grown in chamber slides and treated with a cocktail of ISD and 
analyszed with the LIVE/DEAD Viability/Cytotoxicity Kit (Probes, Eugene, OR, USA). After $48 \mathrm{~h}$ treatment, the cells were collected, washed twice with PBS, stained for $30 \mathrm{~min}$, and visualized under UV light with a BH-2 microscope (Olympus Corp., Melville, NY, USA). This is a fluorescence-based method for determining viability of adherent or non-adherent cells and for assaying cytotoxicity. The assay comprises of two probes: calcein AM and ethidium homodimer-1. Calcein AM is a fluorogenic esterase substrate that is hydrolyzed to a green-fluorescent product (calcein); thus, the emission of green fluorescent light is an indicator of cells that have esterase activity as well as an intact membrane to retain the esterase products. Ethidium homodimer-1 is a high-affinity, redfluorescent nucleic acid stain that is only able to pass through the compromised membranes of dead cells.

\section{Immunostaining for insulin and the active form of caspase-3}

After a $48 \mathrm{~h}$ treatment with or without ISD, cells were fixed for $1 \mathrm{~h}$ at room temperature in 4\% paraformaldehyde in PBS ( $\mathrm{pH} 7 \cdot 4)$. They were then washed in PBS, permeabilized in $0 \cdot 1 \%$ Triton X-100 in $0 \cdot 1 \%$ sodium citrate, rinsed twice in PBS, and incubated with a polyclonal goat anti active form of caspase- 3 antibody (Santa Cruz Biotechnology Inc., Santa Cruz, CA, USA) diluted 1:250 in PBS, or with a polyclonal guinea pig anti-insulin antibody (DAKO Corp., Carpinteria, CA, USA) diluted 1:400. The incubation was performed at $4{ }^{\circ} \mathrm{C}$ overnight. After several washes in PBS, an antigoat fluorescein-conjugated antibody (Probes, Eugene, OR, USA) diluted 1:1500 for the detection of caspase-3, and an anti-guinea pig rhodamine-conjugated antibody (Probes), diluted 1:1500 for the detection of insulin, were incubated for $1 \mathrm{~h}$ at room temperature. To identify the nuclei, the cells were also stained with the karyophilic dye Hoechst $33342(10 \mu \mathrm{g} / \mathrm{ml})$ for $5 \mathrm{~min}$ at room temperature. After a final wash in PBS, the cells were visualized under UV light with a BH-2 microscope (Olympus Corp., Melville, NY, USA) and using a fluorescein standard filter set $(520 \pm 20 \mathrm{~nm})$ for caspase-3 staining and a rhodamine filter $(>620 \mathrm{~nm})$ for insulin.

\section{FACS analysis for Annexin-V}

Apoptotic cells were analyzed by flow cytometer (FACS; Becton Dickinson and Co., San Jose, CA, USA) using the Annexin-V-FLOUS Staining Kit (Roche Diagnostic Corporation, Indianapolis, IN, USA). Annexin-V is a $\mathrm{Ca}^{2+}$-dependent phospholipid-binding protein with a high affinity for phosphotidylserine (PS); hence, this protein can be used as a probe for PS exposure on the outer leaflet of the cell membrane and can be used for the detection of apoptotic cells. The simultaneous application of propidium iodide as a DNA stain, used for dye exclusion tests, allows Annexin- $\mathrm{V}$ positively stained cells to be distinguished from necrotic cells. Cells were collected from the culture flasks and washed twice with PBS by centrifugation at $200 \boldsymbol{g}$ for $5 \mathrm{~min}$. The cell pellet was then suspended in $100 \mu \mathrm{l}$ of staining solution and incubated for $15 \mathrm{~min}$ at room temperature. Flow cytometric analysis was performed with a FACScan cytometer (Becton Dickinson and Co., Franklin Lakes, NJ, USA), using the LYSIS II analyzer program. Exendin (9-39) was purchased from American Peptide Co. (Sunnyvale, CA, USA).

\section{DNA fragmentation analysis}

Floating and adherent cells from each culture condition studied were collected, centrifuged, pelleted at $400 \boldsymbol{g}$ for $5 \mathrm{~min}$, and washed twice with PBS. The pellet was then resuspended in $0.2 \mathrm{ml}$ lysis buffer $(100 \mathrm{mM} \mathrm{NaCl}$, $10 \mathrm{mM}$ Tris $(\mathrm{pH} 8 \cdot 0), 1 \mathrm{mM}$ EDTA, $0.5 \%$ sodium dodecyl sulfate, $0 \cdot 20 \mathrm{mg} / \mathrm{ml}$ proteinase $\mathrm{K}, 200 \mu \mathrm{g} / \mathrm{ml}$ ribonuclease A). The cell lysates were incubated at $37^{\circ} \mathrm{C}$ for $2 \mathrm{~h}$. The genomic DNA was extracted by two separations with phenol/chloroform, followed by one extraction with chloroform alone. The DNA pellet was then washed in 70\% ethanol and resuspended in $1 \mathrm{mM}$ EDTA and $10 \mathrm{mM}$ Tris- $\mathrm{HCl}(\mathrm{pH} 8.0)$ at a final concentration of $20 \mu \mathrm{g} / \mathrm{ml}$. The DNA fragmentation analysis was performed using a $1.5 \%$ agarose gel in $1 \mathrm{mM}$ EDTA, $40 \mathrm{mM}$ Tris acetate $(\mathrm{pH} 7 \cdot 6)$ to visualize the laddering of the samples.

\section{Western blot analysis}

Cell pellets were lysed at $4{ }^{\circ} \mathrm{C}$ in a buffer containing $60 \mathrm{mM}$ Tris-HCl (pH 6.8), $1 \%$ sodium dodecyl sulfate, $10 \%$ glycerol, $0.05 \% \quad \mathrm{NP}-40$ and $0.5 \%$ $\beta$-mercaptoethanol and protease inhibitor mixture (1:100 dilution). The lysis buffer for the protein extraction to determine the cytoplasmic abundance of Smac was prepared with the same reagents listed above, without NP-40. Lysates were cleared at 12000 r.p.m. for $15 \mathrm{~min}$ at $4{ }^{\circ} \mathrm{C}$ and stored at $-80{ }^{\circ} \mathrm{C}$ until used. The protein concentration was determined using a Comassie dye assay (Bio Rad, Hercules, CA, USA), and BSA (Sigma Aldrich) was used as a standard. The cell lysates ( $25 \mu \mathrm{g}$ per sample) were then separated by $8 \%$ or $12 \%$ SDS-PAGE under reducing conditions and electrotransferred onto Hybond-G nitrocellulose membrane (Bio Rad) using standard procedures. The membranes were incubated for 2-4 h at room temperature with TBST (20 mM Tris-HCl (pH 7.5), $150 \mathrm{mM} \mathrm{NaCl,} 0 \cdot 2 \%$ Tween-20) detection reagent. Primary antibodies were used at the following dilutions: anti Bcl-2 (1:500); anti poly-(ADP-ribose)-polymerase (PARP; 1:500); anti second mitochondria-derived activator of caspase Smac/ DIABLO (1:400); anti active form of caspase-3 (1:1000); 


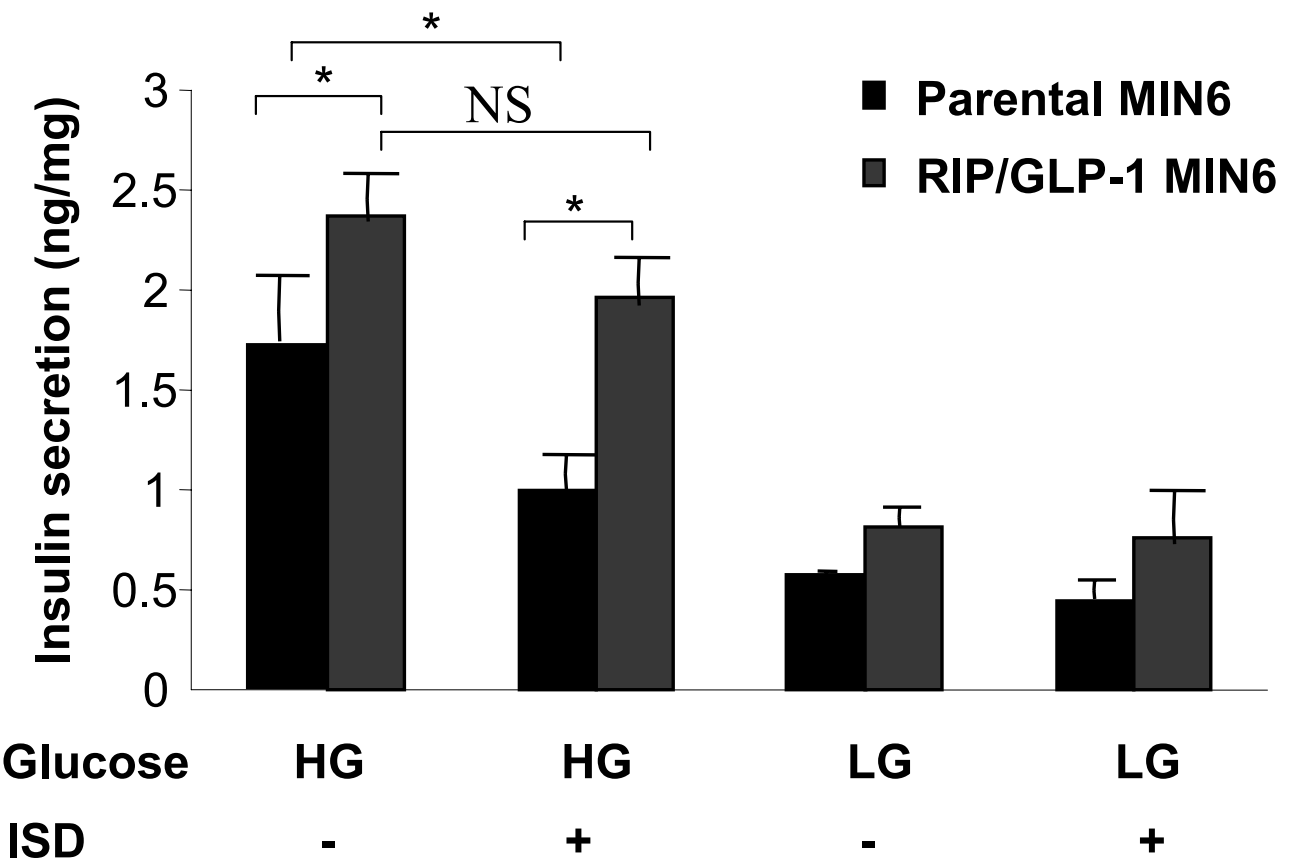

Figure 1 Effect of ISD on glucose-stimulated insulin secretion: constitutive expression of GLP-1 counteracts the negative effect of ISD on glucose-dependent insulin secretion. Parental and RIP/GLP-1 MIN6 cells were cultured for $48 \mathrm{~h}$ in the presence or absence of ISD (sirolimus (25 ng/ml), mycophenolate $(17.5 \mathrm{ug} / \mathrm{ml}$ ) and tacrolimus $(75 \mathrm{ng} / \mathrm{ml})$ ). After a $2 \mathrm{~h}$ washout with medium (in the absence of FBS and glucose), the cells were challenged with either 5.6 or $16.7 \mathrm{mM}$ glucose. Each experiment was repeated at least four times, and the data plotted on the graph represent the mean $\pm S$.E. Insulin levels were normalized for total proteins from cell extracts. ${ }^{*} P<0.01$; NS=not significant.

and anti $\beta$-actin (1:1000). All antibodies were purchased from Santa Cruz Biotechnology Inc.

\section{Measurement of GLP-1 secretion}

Parental and RIP/GLP-1 MIN6 cells utilized to perform FACS analysis for Annexin-V were also used to evaluate the concentration of GLP-1 in their culture medium. GLP-1 was measured by RIA (Linco Research Inc., St Charles, MA, USA).

\section{Statistical analysis}

The data were expressed as mean \pm S.E. Comparisons of means of multiple groups were made using one-way ANOVA followed by post hoc analysis using Fisher's least significant difference method.

\section{Results}

\section{GLP-1 counteracted the negative effects of ISD on glucose-dependent insulin secretion}

The exposure of parental MIN6 cells to a cocktail of ISD for $48 \mathrm{~h}$ produced a significant reduction of their ability to secrete insulin after glucose challenge. Indeed, when parental MIN6 cells were exposed (for $1 \mathrm{~h}$ ) to medium containing $16.7 \mathrm{mM}$ glucose (after a $2 \mathrm{~h}$ wash out with glucose-free, serum-free medium) there was a significantly decrease in the insulin concentration in cultures exposed to ISD $(1.02 \pm 0.21 \mathrm{ng}$ insulin $/ \mathrm{mg}$ pellet protein) compared with cultures exposed to vehicle alone $(1 \cdot 71 \pm 0 \cdot 19 \mathrm{ng}$ insulin/mg pellet protein; $P<0 \cdot 01)$ (Fig. 1). Conversely, RIP/GLP-1 MIN6 cells showed a significant preservation of glucose-dependent secretion of insulin after treatment with ISD. Indeed, exposure of RIP/GLP-1 MIN6 cells to ISD was associated with an accumulation of insulin in the culture medium that was equivalent to approximately $85 \%$ of the total insulin accumulated in the medium of untreated RIP/GLP-1 MIN6 cells (Fig. 1).

\section{GLP-1 preserved the viability of cells exposed to ISD}

\section{Qualitative analysis of the effect of GLP-1 on cell viability}

The viability of parental and RIP/GLP-1 MIN6 cells exposed to either a cocktail of ISD or vehicle for $48 \mathrm{~h}$ was measured using calcein-AM (a membranepermeable dye that in live cells is cleaved by esterases to 



Figure 2 Evaluation of cell survival using the LIVE/DEAD viability/cytotoxicity assay: GLP-1 reduced the percentage of the cell dead induced by exposure to ISD. Parental and RIP/GLP-1 MIN6 cells were cultured for $48 \mathrm{~h}$ in the presence, or absence, of ISD (sirolimus $(25 \mathrm{ng} / \mathrm{ml})$, mycophenolate $(17.5 \mathrm{ug} / \mathrm{ml})$ and tacrolimus $(75 \mathrm{ng} / \mathrm{ml})$ ). The color green in the cell staining identifies the living cells, while the red color identifies the dead cells. (A) parental MIN6 cells cultured in control medium, (B) RIP/GLP-1 MIN6 cells cultured in control medium, $(C)$ parental MIN6 cells cultured in the presence of ISD, (D) RIP/GLP-1 MIN6 cells cultured in the presence of ISD. The pictures shown are representative of three independent experiments which had very similar results. Scale bar $=5 \mu \mathrm{m}$.

yield cytoplasmic green fluorescence) and ethidium homodimer-1 (a red nucleic acid dye to which live cells are impermeable, but that accumulates in the nuclei of membrane-compromised cells) staining. Panel A and B of Figure 2 show that in cultures of both parental MIN6 cells and RIP/GLP-1 MIN6 cells grown without ISD virtually all cells were viable. Both cultures showed a large number of dead cells after exposure to ISD. However, cultures of parental MIN6 cells $(\mathrm{C})$ showed a greater number of dead cells, compared with cultures of RIP/GLP-1 MIN6 cells (D).

\section{Quantitative analysis of the effect of GLP-1 on cell viability}

FACS analysis for Annexin-V of parental and RIP/ GLP-1 MIN6 cells exposed to either ISD or vehicle indicated that the expression of GLP-1 by cells enhanced the percentage of viable cells (Table 1). This experiment indicated that $18 \cdot 83 \pm 5 \%$ of parental MIN6 cells vs. $8.33 \pm 5 \%$ of the RIP/GLP-1 MIN6 cells were Annexin-V-positive when exposed to ISD $(P<0 \cdot 01)$. The transfection of cells with GLP-1 was also associated with significant protection from necrosis induced by ISD
$(P<0 \cdot 01)$ and an overall larger percentage of living cells ( $75.64 \pm 5 \%$ vs. $58 \cdot 51 \pm 5 \%$ in RIP/GLP-1 MIN6 cells vs. parental MIN6, $P<0 \cdot 01)$, after challenge with ISD $(P<0 \cdot 01$; Table 1$)$.

RIA for GLP-1 of the culture medium collected prior to assaying the cell pellet of RIP/GLP-1 MIN6 cells by FACS analysis for Annexin-V revealed the presence of $4 \cdot 6 \pm 1 \cdot 1 \mathrm{nM}$ of GLP-1. No GLP-1 was detected in parental MIN6 cells. The concentration of GLP-1 appeared within the range that in humans with type 2 diabetes has been shown capable of lowering plasma glucose levels (Todd et al. 1997)

\section{GLP-1 inhibited the DNA fragmentation induced by ISD}

Activation of a calcium-dependent endonuclease is one of the earliest detectable events denoting an irreversible commitment to cell death. This results in the characteristic formation of DNA fragments of 180 $200 \mathrm{bp}$. Electrophoresis of genomic DNA from MIN6 cells exposed to ISD showed the characteristic laddering pattern that leads to cell death (Fig. 3). This was in clear 
Table 1 Quantitative analysis of the effect of GLP-1 on cell viability

\begin{tabular}{|c|c|c|c|}
\hline & Living (\%) & Apoptosis (\%) & Necrosis (\%) \\
\hline \multicolumn{4}{|l|}{ Cells and Treatment } \\
\hline MIN6 & $83 \cdot 46 \pm 4$ & $10 \cdot 74 \pm 3$ & $5 \cdot 29 \pm 5$ \\
\hline MIN6 \pm ISD & $58 \cdot 51 \pm 5]$ & $18 \cdot 83 \pm 5]$ & $17 \cdot 60 \pm 5]$ \\
\hline RIP/GLP-1 MIN6 & $86 \cdot 45 \pm 4$ * & $5 \cdot 76 \pm 4$ & $5 \cdot 37 \pm 3$ \\
\hline RIP/GLP-1 MIN6+ISD & $75 \cdot 64 \pm 5$ & $8 \cdot 33 \pm 5$ & $6 \cdot 73 \pm 5$ \\
\hline
\end{tabular}

Percentage of living, necrotic and apoptotic cells (mean \pm S.E.), as derived from at least four independent experiments. Statistical significance of the data was evaluated by Student's $t$ test, and further confirmed by Dunnett's post hoc test. ${ }^{*} P<0.01$.

contrast with the preserved DNA integrity that was observed in RIP/GLP-1 MIN6 cells exposed to ISD.

\section{GLP-1 enhanced the expression of anti-apoptotic proteins and induced a down regulation of pro-apoptotic factors}

GLP-1 increased the intracellular levels of $\mathrm{BCl}-2$

RIP/GLP-1 MIN6 cells exhibited a significantly greater abundance of the anti-apoptotic protein Bcl-2 compared with parental cells (Fig. 4), and its abundance was minimally affected by the exposure of cells to ISD.

GLP-1 inhibits the cleavage of the $p-85$ subunit of PARP

Western blot analysis revealed that in MIN6 exposed to ISD there was a greater abundance of the p85 subunit of PARP, compared with untreated cells (Fig. 4). In comparison, RIP/GLP-1 MIN6 cells cultured in the presence of the ISD showed a significant preservation of the PARP in its inactive form, and exposure of

A

B

C

D E
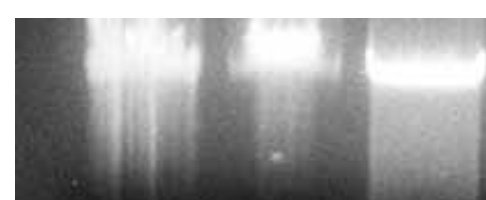

(1)


FBS

ISD

Figure 3 GLP-1 inhibited DNA fragmentation induced by ISD. Parental and RIP/GLP-1 MIN6 cells were cultured for $48 \mathrm{~h}$ in the presence or absence of ISD (sirolimus (25 ng/ml), mycophenolate (17.5 ug/ml) and tacrolimus $(75 \mathrm{ng} / \mathrm{ml})$ ). (A) parental MIN6 cells cultured in regular medium, (B) parental MIN6 cells cultured in the absence of FBS, (C) parental MIN6 cells cultured in the absence of FBS and in the presence of ISD, (D) RIP/GLP-1 MIN6 cells cultured in the absence of FBS, (E) RIP/GLP-1 MIN6 cells cultured in the absence of FBS and in the presence of ISD. Each experiment was repeated at least three times, and the blot presented is representative of three independent experiments. 


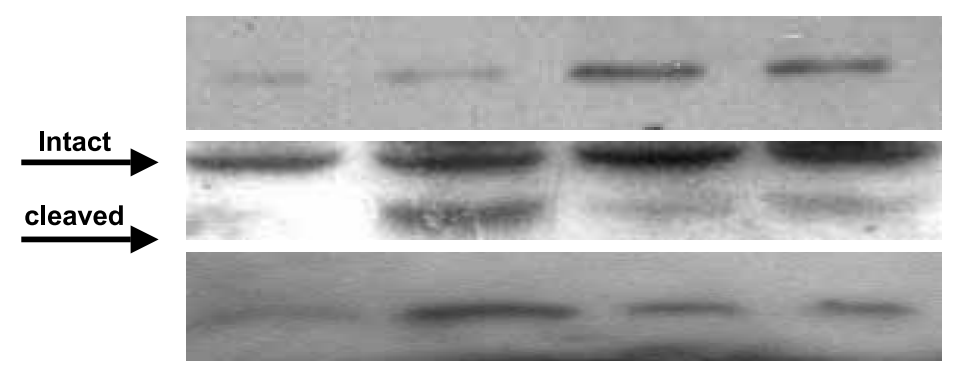

\section{$\mathrm{Bcl}-2$}

\section{PARP}

\section{Smac}

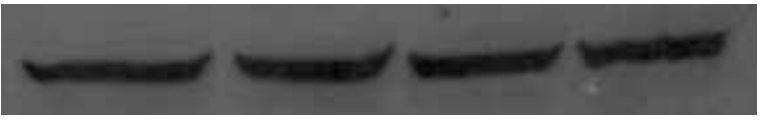

\section{ß-actin}
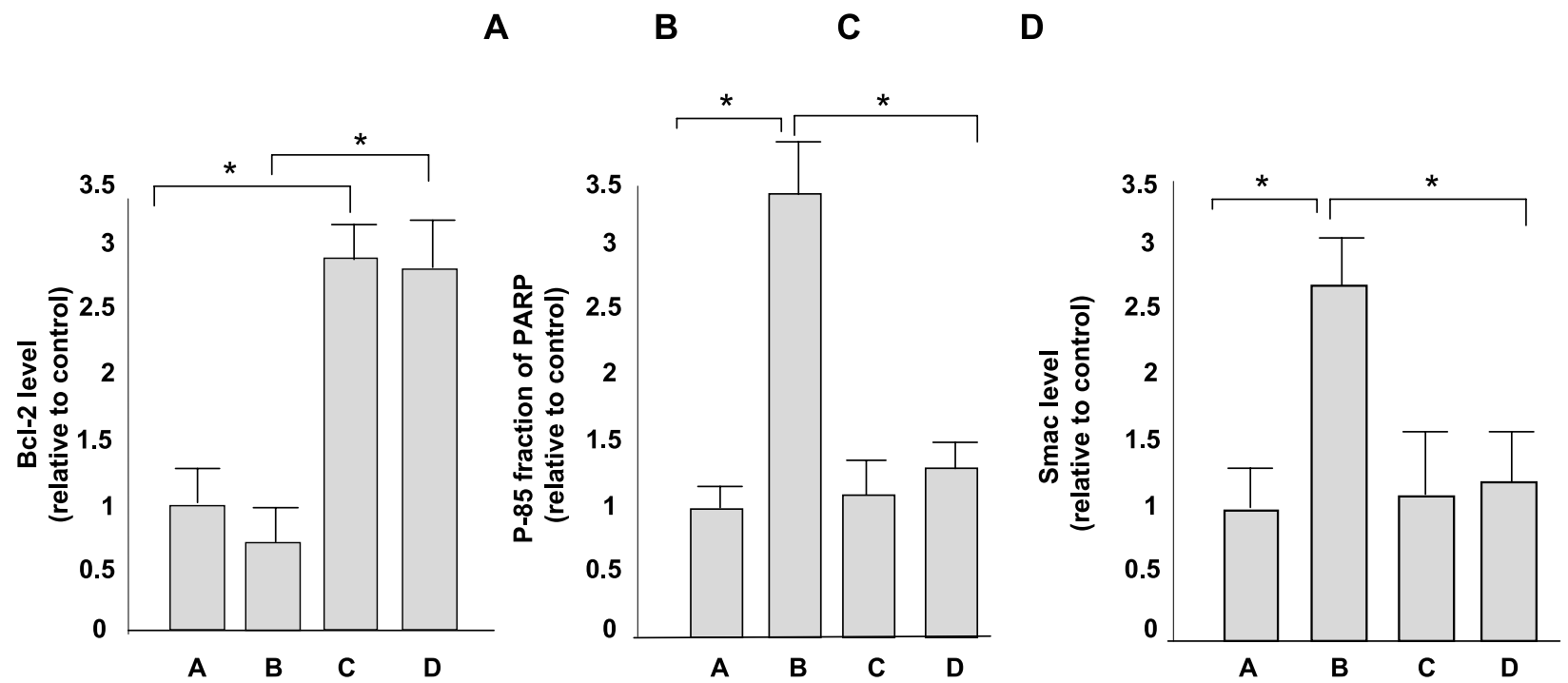

Figure 4 GLP-1 enhanced the expression of $\mathrm{Bcl}-2$ and inhibited the expression of the pro-apoptotic proteins PARP-p85 and Smac. Parental and RIP/GLP-1 MIN6 cells were cultured for $48 \mathrm{~h}$ in the presence or absence of ISD (sirolimus (25 $\mathrm{ng} / \mathrm{ml})$, mycophenolate $(17.5 \mathrm{ug} / \mathrm{ml})$ and tacrolimus $(75 \mathrm{ng} / \mathrm{ml}))$. After protein extraction, the samples were subjected to western blot analysis for Bcl-2, PARP, Smac and $\beta$-actin. (A) parental MIN6 cells cultured in control medium, (B) parental MIN6 cells cultured in the presence of ISD, (C) RIP/GLP-1 MIN6 cells cultured in control medium, (D) RIP/GLP-1 MIN6 cells cultured in the presence of ISD. The blots on the top are representative of four independent experiments. The graphs on the bottom represent the average of four independent western blotting experiments. Protein levels were normalized for $\beta$-actin level and are shown in the graphs as fold difference, compared with control (A). ${ }^{\star} P<0.01$.

RIP/GLP-1 MIN6 cells did not alter the intracellular level of p85.

\section{GLP-1 prevents the mitochondrial release of Smac/DIABLO}

Parental MIN6 exposed to the cocktail of ISD for $48 \mathrm{~h}$ exhibited a significant increase in Smac/DIABLO levels compared with untreated cultures (Fig. 4). This effect was significantly reduced in RIP/GLP-1 MIN6 cells, even after exposure to ISD.

\section{GLP-1 inhibits the activation of caspase-3}

The exposure of parental MIN6 cells to ISD produced a detectable activation of caspase-3, as determined by immunostaining (Fig. 5, top panel). Conversely, RIP/ GLP-1 MIN6 cells were resistant to the activation of caspase-3 after exposure to ISD.

Western blot analysis for the active form of caspase-3 further confirmed the observation derived from the immunofluorescence study (Fig. 5, bottom panel), and demonstrated that while in parental MIN6 cells the exposure to ISD produced a $4 \cdot 5$-fold increase in the intracellular level of the active form of caspase-3 (ISD-treated cells vs. cells cultured with vehicle alone; $P<0 \cdot 001)$, the effect of ISD on RIP/GLP-1 MIN6 cells was less pronounced. Indeed, RIP/GLP-1 MIN 6 cells showed an induction in the activation of caspase- 3 of 1.9 fold when compared with cells cultured with vehicle alone $(P<0 \cdot 01)$, and this was equivalent to 
MIN6
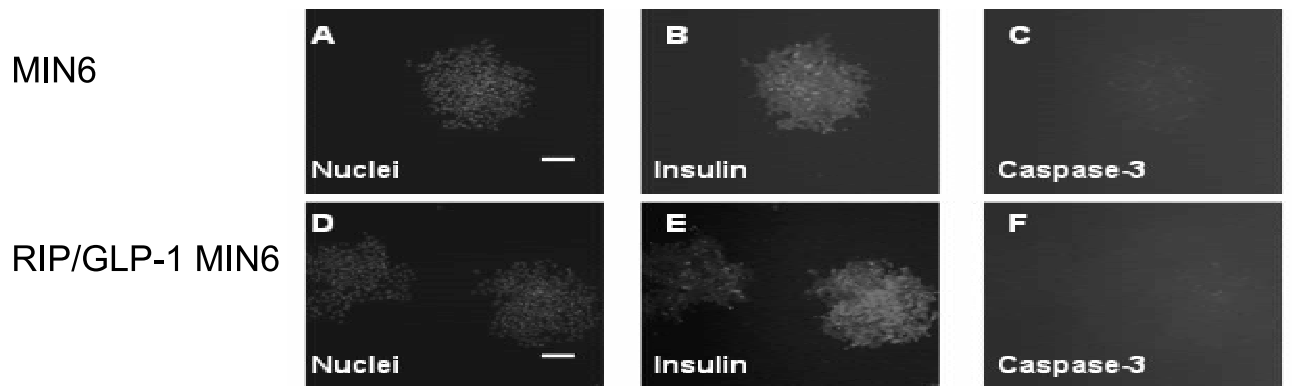

MIN6
+ ISD
RIP/GLP-1 MIN6
+ ISD
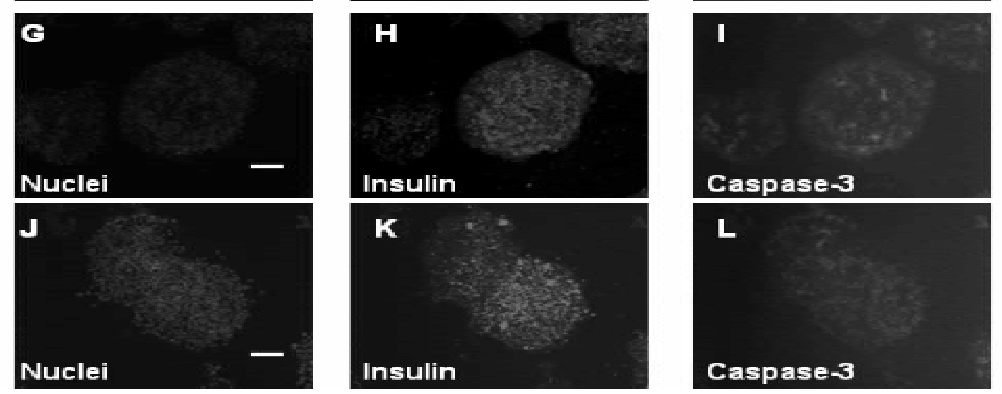

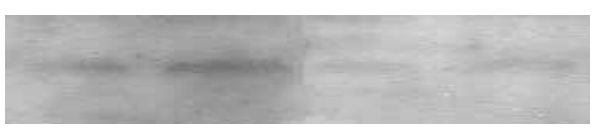

caspase-3

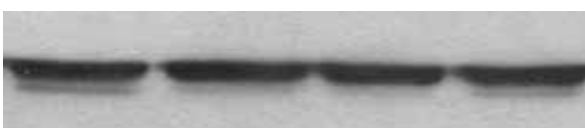

$\beta$-actin

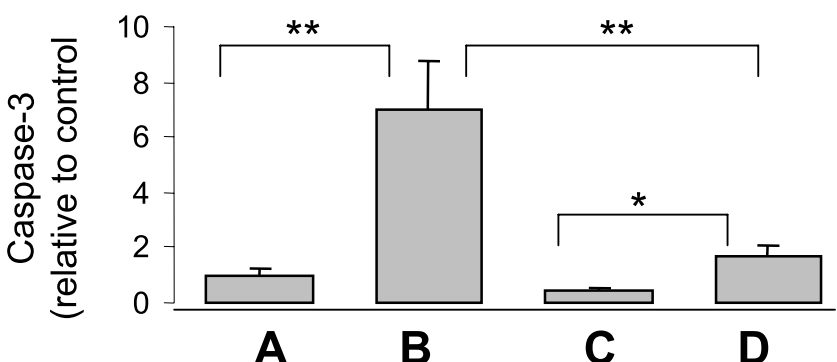

\section{A B $\quad$ C $\quad$ D}

Figure 5 GLP-1 reduced cellular expression of active form of caspase-3. Top panels, immunofluorescence for nuclei (blue), insulin (red) and caspase-3 (green). A-C, immunostaining of parental MIN6 cells; A, Hoechst nuclear staining; B, insulin; C, caspase-3; D-F, immunostaining of RIP/GLP-1 MIN6 cells; D, Hoechst nuclear staining; E, insulin; F, caspase-3; G-I, immunostaining of parental MIN6 cells (cultured in the presence of ISD; sirolimus $(25 \mathrm{ng} / \mathrm{ml})$, mycophenolate $(17.5 \mathrm{ug} / \mathrm{ml})$ and tacrolimus $(75 \mathrm{ng} / \mathrm{ml})$ for 48 hours); G, Hoechst nuclear staining; H, insulin; I, caspase-3; J-L, immunostaining of RIP/GLP-1 MIN6 cells cultured in the presence of ISD; J, Hoechst nuclear staining; K, insulin; L, caspase-3. Scale bar $5 \mu$. Each experiment was repeated at least three times, and the pictures shown are representative of three independent experiments. Bottom panels, western blot analysis for the active form of caspase-3. Parental and RIP/GLP-1 MIN6 cells were cultured for $48 \mathrm{~h}$ in the presence or absence of ISD. After protein extraction, the samples were subjected to western blot analysis for the active form of caspase-3 and $\beta$-actin. A, parental MIN6 cells cultured in control medium; B, parental MIN6 cells cultured in the presence of ISD; C, RIP/GLP-1 MIN6 cells cultured in control medium; D, RIP/GLP-1 MIN6 cells cultured in the presence of ISD. The blot on the left is representative of three independent experiments. The graph on the right represents the average of three independent experiments. Protein levels were normalized for $\beta$-actin level and are shown in the graphs as fold difference, compared with control $(A)$. ${ }^{*} P<0 \cdot 01 ;{ }^{* *} P<0 \cdot 001$.

approximately $60 \%$ lower than parental MIN6 cells cultured under the same conditions (ISD-treated MIN6 cells vs. ISD-treated RIP/GLP-1 MIN6 cells, $P<0 \cdot 001)$.

\section{The anti-apoptotic effect of GLP-1 was independent from its effect on insulin secretion}

In order to investigate whether the capability of RIP/GLP-1 MIN6 cells to counteract the pro-apoptotic action of ISD was a direct effect of GLP-1, or whether it was the result of a greater secretion of insulin in cells expressing GLP-1, we cultured cells in the presence of diazoxide $(250 \mu \mathrm{M} / \mathrm{L}$ for $48 \mathrm{~h})$, an agent known to inhibit insulin secretion. The viability of cells was investigated using the DNA laddering assay and their capability to secrete insulin was measured using a RIA. We demonstrated that, while diazoxide was effective in suppressing the secretion of insulin $(2 \cdot 36 \pm 0.21 \mathrm{ng}$ of insulin/mg of protein in untreated cultures vs. $0.41 \pm 0.07 \mathrm{ng}$ of insulin $/ \mathrm{mg}$ of protein; $P<0.01$ ), its 
action did not diminish the resistance of RIP/GLP-1 MIN6 cells to the pro-apoptotic action of ISD (Fig. 6, lanes D vs. E).

Parental MIN6 cells exposed to ISD showed the characteristic laddering pattern that leads to cell death (Fig. 6, lane G). In contrast, RIP/GLP-1 MIN6 cells did not show DNA fragmentation when exposed to ISD. These results supported the hypothesis that the antiapoptotic role of GLP-1 on the cells exposed to a cocktail of ISD was independent from its effect on the stimulation of insulin secretion.

\section{Inhibition of GLP-1 receptor activation by exendin 9 abolished the effect of GLP-1 on the viability of cells exposed to ISD}

To investigate whether the capability of RIP/GLP-1 MIN6 cells to counteract the proapoptotic effect of ISD was specifically mediated by the activation of the GLP-1 receptor, cells were cultured in medium containing increasing concentrations of the receptor antagonist exendin-9. FACS analysis for Annexin V demonstrated that $19 \cdot 60 \pm 2 \%$ of parental MIN6 cells vs. $8 \cdot 34 \pm 2 \cdot 3 \%$ of RIP/GLP-1 MIN6 cells were Annexin-V-positive when cultured for $48 \mathrm{~h}$ in medium containing ISD $(P<0 \cdot 01)$ (Fig. 7). The cell survival advantage that RIP/GLP-1 MIN6 cells had when compared with parental MIN6 cells was abolished by the presence of exendin 9 in the culture medium. Indeed, as the concentration of exendin 9 in the medium was increased, the difference in the percentage of living cells between the two cell lines (RIP/GLP-1 MIN6 cells and parental MIN6 cells) became no longer significant. The capability of exendin-9 to inhibit cell death reached its plateau at the concentration of $10 \mathrm{nM}$, and at that concentration the percentage of death cells was very similar among cultures $(43 \cdot 4 \pm 2 \cdot 1$ vs. $41 \cdot 7 \pm 1 \cdot 9$, in parental vs. RIP/GLP-1 MIN6 cells, respectively) (Fig. 7).

These results demonstrate that the inhibition of the activation of the GLP-1 receptor abolish the capability of RIP/GLP-1 MIN6 cell to counteract the pro-apoptotic action of ISD.

\section{GLP-1 induced a dose-dependent inhibition of cell death}

To investigate the dose-dependent inhibition of cell death by GLP-1 we cultured parental MIN6 cells in the presence of various concentration of GLP-1 (for $48 \mathrm{~h}$ ) and then exposed each culture condition to ISD (for an additional $48 \mathrm{~h}$ ). In addition to defining the dose response for GLP-1's effect on cell viability, the aim of this experiment was to investigate whether the observed capability of RIP/GLP-1 MIN6 to be protected against the toxic effect of ISD was due to the specific action of
GLP-1, or whether it was the result of a clonal selection that rendered the transfected cell line less susceptible to cell death. FACS analysis for Annexin-V demonstrated the presence of a dose-dependent inhibition of cell death by GLP-1 (Fig. 8). The presence of $1 \mathrm{nM}$ GLP-1 in the culture medium was sufficient to produce a statistically significant inhibition of cell death $(38 \%$ vs. $29 \cdot 7 \%$ in control vs. GLP-1 treated cultures, respectively; $P<0 \cdot 01$ ) and it further increased in a dose-dependent fashion in cultures grown in 5, 10 or $100 \mathrm{nM}$ of GLP-1.

\section{Discussion}

In the present study we demonstrated that some of the most important immunosuppressive drugs used after islets transplantation have a negative effect on function and viability of insulin-producing cells. The presence of immunosuppressive agents in the culture medium of MIN6 cells altered their glucose-dependent capability to secrete insulin, and caused a significant increase in the number of cells undergoing apoptosis and necrosis. This complex set of biological effects was significantly reduced by the transfection of cells with a plasmid expressing the GLP-1 fragment of the human proglucagon gene.

Our findings are consistent with previous reports describing deterioration in islet function and viability in response to tacrolimus, sirolimus and mycophenolate. Drachenberg et al. (1999) performed electron microscopy studies of pancreatic biopsies from patients subjected to pancreas and kidney transplantation and showed that treatment with tacrolimus was associated with an increased cytoplasmic swelling, cellular vacuolization, and a marked decrease in dense-core secretory granules of islet cells. Paty et al. (2002) demonstrated that mycophenolate and tacrolimus had deleterious effects on insulin secretion in both HITT15 cells and cultured rat islets. In addition to inhibiting insulin secretion (Ricordi et al. 1991, Strasser et al. 1992, Ishizuka et al. 1993), tacrolimus has been shown to down regulate the synthesis of insulin (Redmon et al. 1996). Mycophenolate has been shown to reduce insulin secretion by inhibiting voltage-dependent calcium channels (Meredith et al. 1997, Li et al. 2000). On the other hand, sirolimus has been shown to have a very modest adverse effect on islet function (Fabian et al. 1992, Kneteman et al. 1995); and a reduction in insulin release has been demonstrated only after a prolonged culture with a high concentration of the drug (Fabian et al. 1992). Prior observations from various laboratories have shown that GLP-1 was capable of inducing the expression of anti-apoptotic proteins leading to improved survival of cells. Li et al. (2003) have shown that GLP-1 receptor signaling modifies the susceptibility of mice to undergo islet cell apoptosis after treatment with streptozotocin. Farilla et al. (2002) have demonstrated that GLP-1 reduced the number of 

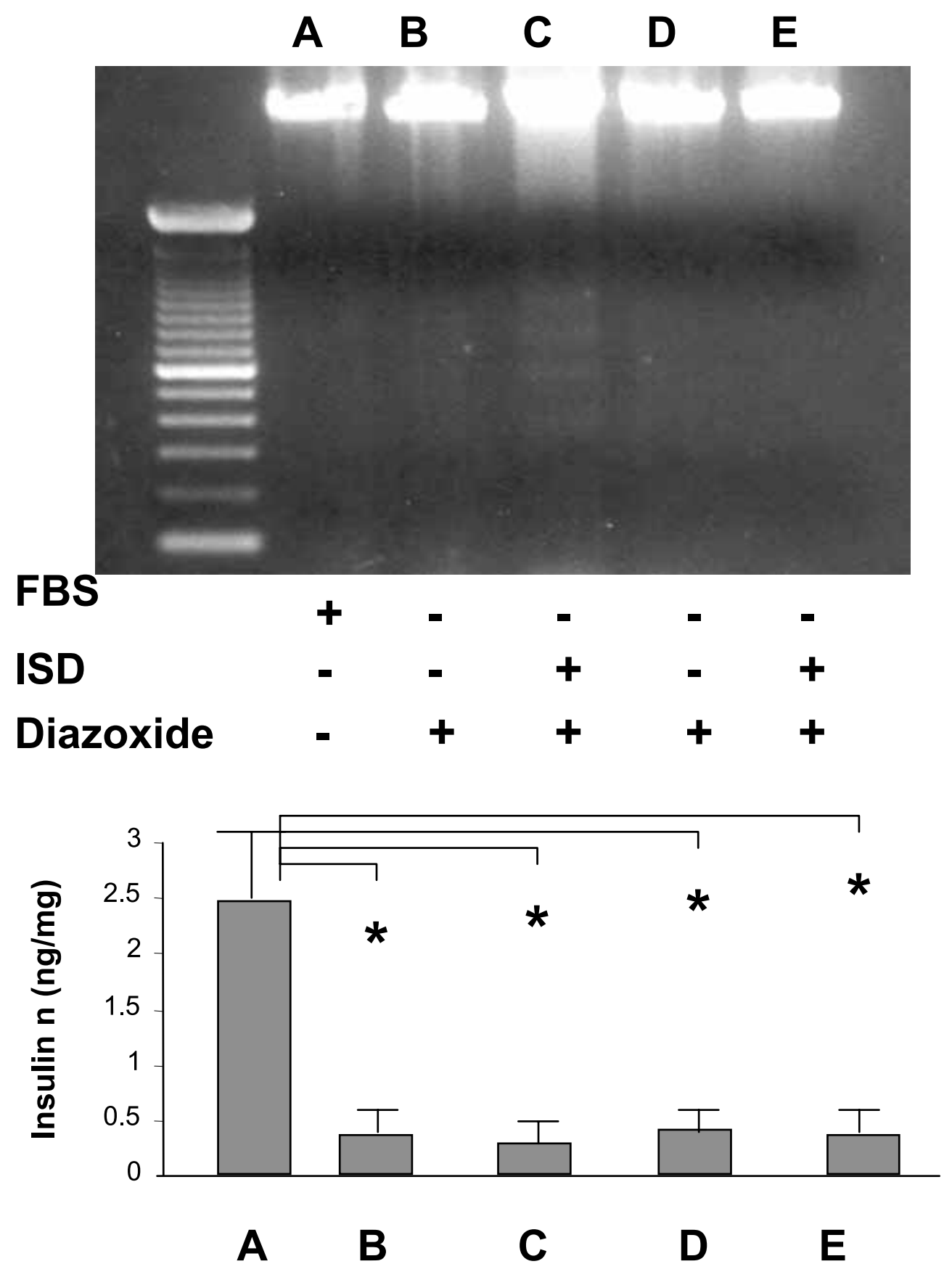

Figure 6 The anti apoptotic effect of GLP-1 is not blocked by the inhibition of insulin secretion. Parental and MIN6 RIP/GLP-1 cells were cultured for $48 \mathrm{~h}$ in the presence or absence of diazoxide $(250 \mu \mathrm{M} / \mathrm{L})$ and in the presence or absence of ISD (sirolimus $(25 \mathrm{ng} / \mathrm{ml})$, mycophenolate $(17.5 \mathrm{ug} / \mathrm{ml})$ and tacrolimus $(75 \mathrm{ng} / \mathrm{ml}))$. On the top, DNA fragmentation assay. A, parental MIN6 cells cultured in regular medium; B, parental MIN6 cells cultured in the presence of diazoxide; C, parental MIN6 cultured in the presence of diazoxide and in the presence of ISD; D, RIP/GLP-1 MIN6 cells cultured in the presence of diazoxide; E, RIP/GLP-1 MIN6 cells cultured in the presence of diazoxide and in the presence of ISD. On the bottom, insulin secretion assay. A, parental MIN6 cells cultured in regular medium; B, parental MIN6 cells cultured in the presence of diazoxide; C, parental MIN6 cultured in the presence of diazoxide and in the presence of ISD; D, RIP/GLP-1 MIN6 cells cultured in the presence of diazoxide; E, RIP/GLP-1 MIN6 cells cultured in the presence of diazoxide and in the presence of ISD. Each experiment was repeated at least three times and the data plotted on the graph represent the mean \pm S.E. ${ }^{\star} P<0.01$ 

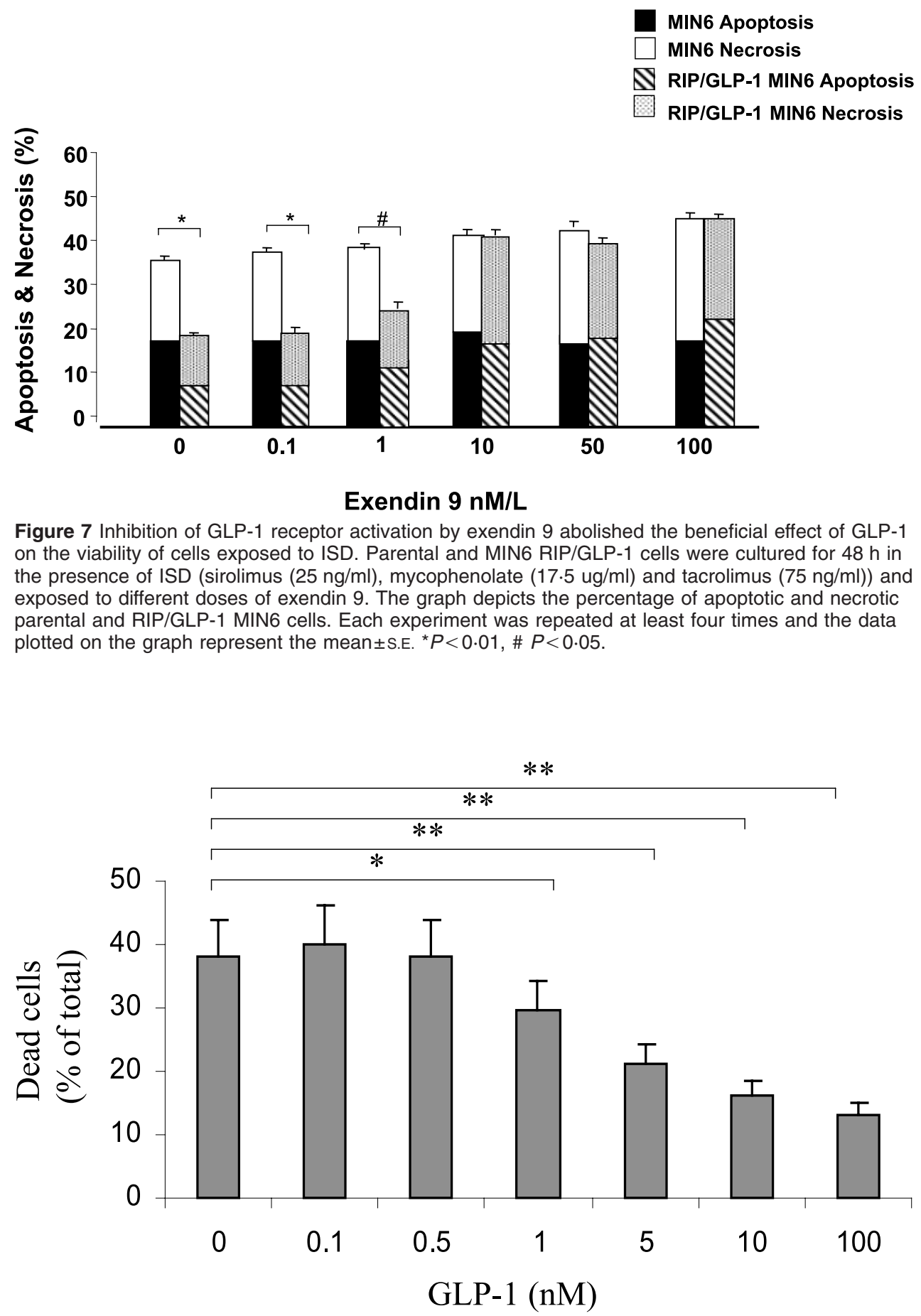

Figure 8 Dose-dependent inhibition of cell death by GLP-1. Parental MIN6 cells were cultured for $48 \mathrm{~h}$ in the presence of various concentration of GLP-1 $(0,0.1,0.5,1,5,10,100 \mathrm{mM})$. A $10 \mu \mathrm{l}$ aliquot of GLP-1 was added every $8 \mathrm{~h}$, without changing the culture medium. After $48 \mathrm{~h}$, the old medium was discarded and replaced with fresh medium containing various concentration of GLP-1 in the presence of ISD (sirolimus $(25 \mathrm{ng} / \mathrm{ml})$, mycophenolate $(17.5 \mathrm{ug} / \mathrm{ml})$ and tacrolimus $(75 \mathrm{ng} / \mathrm{ml})$ ) for an additional period of $48 \mathrm{~h}$. At the end of this second incubation period the medium was discarded and the pellet assayed for cell viability by FACS analysis for Annexin-V. The graph depicts the percentage of apoptotic and necrotic cells. Each experiment was repeated at three times, and the data plotted on the graph represent the mean \pm S.E ${ }^{\star} P<0.01,{ }^{\star *} P<0.001$. 




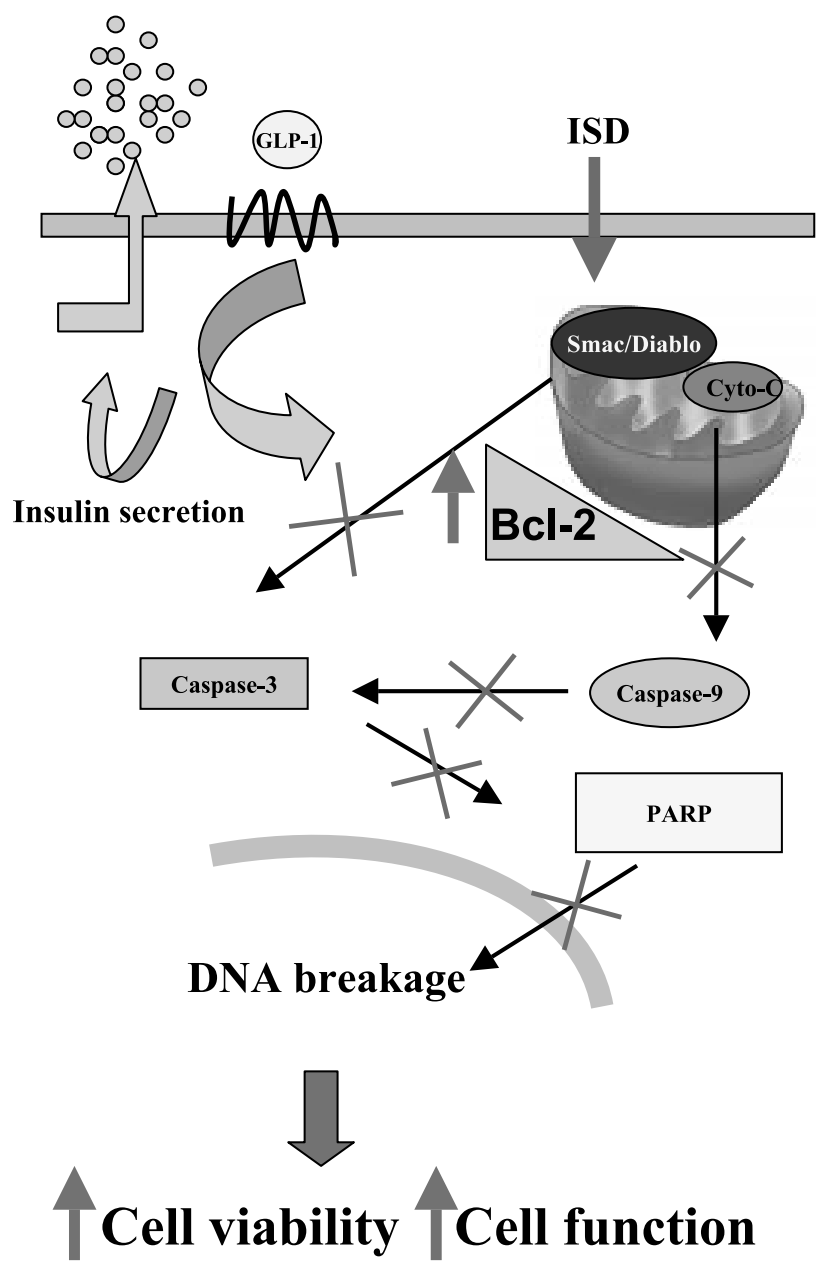

RIP/GLP-1 MIN6 cells

Figure 9 Schematic of ISD effect in parental and GLP-1 transfected MIN6 cells. The exposure of parental MIN6 cells to immunosuppressive agents is associated with the release of Smac/Diable from the mitochondria, an increased detection of the active form of caspase-3 and increased production of the p85 subunit of PARP (left panel). The transfection of MIN6 cells with the GLP-1 fragment of the proglucagon gene is associated with an increased expression of Bcl-2, a decreased cytosolic level of Smac, a down regulation of the levels of the active form of caspase-3 and a decreased abundance of the p85 fraction of PARP (right panel).

apoptotic cells in the pancreas of Zucker diabetic rats, and that GLP-1 when added to freshly isolated human islets or cultured MIN6 cells preserved cell morphology, enhanced insulin synthesis, and improved the cellular capability of secreting insulin in response to glucose (Farilla et al. 2003, Hui et al. 2003). Interestingly, a protective effect of GLP-1 from cellular apoptosis has also been shown on cells other than the pancreatic endocrine cells, as for the neuronal cells of hippocampus (During et al. 2003).

In the present report, studying factors that may mediate the anti-apoptotic action of GLP1, we investigated its effect on some of the main regulators of cell apoptosis, including Bcl-2, caspase-3, PARP, and Smac.

Bcl-2 is member of a class of proteins that are mainly localized at the outer mitochondrial membrane and its expression is associated with inhibition of cell apoptosis. Our study demonstrates that in $\beta$-cells transfected with a plasmid encoding for GLP-1 there was a constitutive activation of the expression of $\mathrm{Bcl}-2$. This observation is consistent with studies by Contreras (2001) and Rabinovitch (1999) showing that the overexpression of Bcl-2 confers a long-term protection of islet mass after transplantation (Rabinovitch et al. 1999, Contreras et al. 2001). 
All apoptotic pathways, so far identified, converge toward the activation of cytoplasmic cystine proteases named caspases and of the various caspases identified, caspase- 3 is one of those that better correlates with cell apoptosis. PARP is involved in the regulation of various important cellular processes such as differentiation, proliferation, and tumor transformation and also in the regulation of the molecular events involved in the recovery of cells from DNA damage (Uchida et al. 2001). In our study, we demonstrated that the exposure of MIN6 cells to immunosuppressive agents was associated with an increased detection of the active form of caspase- 3 and an increased production of the p85 subunit of PARP. In cells transfected with GLP-1 the expression of the active form of caspase- 3 and of PARPp85 were significantly reduced (Fig. 9).

GLP-1 also inhibited the release of Smac/DIABLO, a dimeric mitochondrial protein released into the cytosol along with cytochrome-c during the execution phase of the intrinsic pathway of apoptosis. Because the release of Smac has been proposed to directly enable caspase-3 activation, its detection is an additional indication that a death signal is activated and its down regulation in cells transfected with GLP-1 is a further evidence of an increase resistance against the pro-apoptotic action of immunosuppressive drugs.

Finally, we demonstrated that the capability of GLP-1 transfected MIN6 cells to be resistant to the proapoptotic action of immunosuppressive agents was directly mediated by the autocrine production of GLP-1 and it was not due to its effect on the secretion of insulin.

In summary, our results suggest that GLP-1 is a powerful antiapoptotic agent capable of protecting cells from damage induced by immunosuppressive drugs. These observations may have important clinical and therapeutic implications as GLP-1 is being considered as a potential pharmacological agent for the treatment of diabetes.

\section{Acknowledgments}

This study was supported, in part, by the Max Factor Family Foundation.

\section{References}

Bennet W, Sundberg B, Groth CG, Brendel MD, Brandhorst D, Brandhorst H, Bretzel RG, Elgue G, Larsson R, Nilsson B \& Korsgren O 1999 Incompatibility between human blood and isolated islets of Langerhans: a finding with implications for clinical intraportal islet transplantation? Diabetes 48 1907-1912.

Contreras JL, Bilbao G, Smyth CA, Jiang XL, Eckhoff DE, Jenkins SM, Thomas FT, Curiel DT \& Thomas JM 2001 Cytoprotection of pancreatic islets before and soon after transplantation by gene transfer of the anti-apoptotic Bcl-2 gene. Transplantation $\mathbf{7 1}$ $1015-1023$.
Drachenberg CB, Klassen DK, Weir MR, Wiland A, Fink JC, Bartlett ST, Cangro CB, Blahut S \& Papadimitriou JC 1999 Islet cell damage associated with tacrolimus and cyclosporine: morphological features in pancreas allograft biopsies and clinical correlation. Transplantation 68 396-402.

Drucker DJ 2003 Glucagon-like peptides regulators of cell proliferation, differentiation, and apoptosis. Molecular Endocrinology $17161-171$

During MJ, Cao L, Zuzga DS, Francis JS, Fitzsimons HL, Jiao X, Bland RJ, Klugmann M, Banks WA, Drucker DJ \& Haile CN 2003 Glucagon-like peptide-1 receptor is involved in learning and neuroprotection. Nature Medicine 9 1173-1179.

Fabian MC, Lakey JR, Rajotte RV \& Kneteman NM 1992 Rapamycin prolongs murine islet al.lograft survival. Transplantation Proceedings 242842.

Farilla L, Hui H, Bertolotto C, Bulotta A, Kang E, Di Mario U \& Perfetti R 2002 GLP-1 promotes islet cells growth and inhibits cell apoptosis in Zucker diabetic rats. Endocrinology 143 4397-4408.

Farilla L, Bulotta A, Hirshberg B, Li Calzi S, Khoury N, Noushmehr H, Bertolotto C, Di Mario U, Harlan DM \& Perfetti R 2003 Glucagon-like peptide 1 inhibits cell apoptosis and improves glucose responsiveness of freshly isolated human islets. Endocrinology 144 5149-5158.

Hering B \& Ricordi C 1999 Islet transplantation for patients with type 1 diabetes. Graft 2 12-27.

Herold KC, Nagamatsu S, Buse JB, Kulsakdinun P \& Steiner DF 1993 Inhibition of glucose-stimulated insulin release from beta TC3 cells and rodent islets by an analog of FK506. Transplantation 55 186-192.

Hui H, Yu R, Bousquet C \& Perfetti R 2002 Transfection of pancreatic-derived $\beta$-cells with a minigene encoding for human glucagon-like peptide-1 regulates glucose-dependent insulin synthesis and secretion. Endocrinology 143 3529-3539.

Hui H, Nourparvar A, Zhao X \& Perfetti R 2003 Glucagon-Like Peptide-1 Inhibits Apoptosis of Insulin-Secreting Cells via a Cyclic 5'-Adenosine Monophosphate-Dependent Protein Kinase A-and a Phosphatidylinositol 3-Kinase-Dependent Pathway Endocrinology 144 1444-1455.

Hui H, Khoury N, Zhao X, D' Amico E, Bulotta A, Nguyen E \& Perfetti R 2004 Adenovirus-mediated XIAP gene transfer reverses the negative effects of immunosuppressive drugs on insulin secretion and viability of isolated human islets and MIN6 cells. 64th Annual Meeting of American Diabetes Association, Orlando, FL.

Hussain MA \& Habener JF 2000 Glucagon-like peptide 1 increases glucose-dependent activity of the homeoprotein IDX-1 transactivating domain in pancreatic $\beta$-cells. Biochemical and Biophysical Research Communications 11 616-619.

Ishizuka J, Gugliuzza KK, Wassmuth Z, Hsieh J, Sato K, Tsuchiya T, Townsend CM Jr, Fish JC \& Thompson JC 1993 Effects of FK506 and cyclosporine on dynamic insulin secretion from isolated dog pancreatic islets. Transplantation $\mathbf{5 6}$ $1486-1490$.

Kneteman NM, Lakey JR, Wagner T \& Finegood D 1995 Beneficial metabolic impact of the novel immunosuppressant rapamycin in chronic canine islet autograft recipients. Transplantation Proceedings 27 3213-3217.

Lakey JR, Warnock GL, Shapiro AM, Korbutt GS, Ao Z, Kneteman NM \& Rajotte RV 1999 Intraductal collagenase delivery into the human pancreas using syringe loading or controlled perfusion. Cell Transplant 8 285-292.

Li GD, Luo RH \& Metz SA 2000 Effects of inhibitors of guanine nucleotide synthesis on membrane potential and cytosolic free $\mathrm{Ca} 2+$ levels in insulin-secreting cells. Biochemical Pharmacology $\mathbf{5 9}$ $545-556$.

Li Y, Hansotia T, Yusta B, Ris F, Halban PA \& Drucker DJ 2003 Glucagon-like peptide-1 receptor signaling modulates $\beta$ cell apoptosis. Fournal of Biological Chemistry 278 471-478. 
Meredith M, Li G \& Metz SA 1997 Inhibition of calcium-induced insulin secretion from intact HIT-T15 or INS-1 beta cells by GTP depletion. Biochemical Pharmacology 53 1873-1882.

Patty BW, Harmon JS, Marsh LC \& Robertson RP 2002 Inhibitory effect of immunosuppressive drugs on insulin secretion from HIT-T15 cells and Wistar rat islets. Transplantation 353-357.

Rabinovitch A, Suarez-Pinzon W, Strynadka K, Ju Q, Edelstein D, Brownlee M, Korbutt GS \& Rajotte RV 1999 Transfection of human pancreatic islets with an anti-apoptotic gene (Bcl-2) protects beta-cells from cytokine-induced destruction. Diabetes $\mathbf{4 8}$ $1223-1229$.

Redmon JB, Olson LK, Armstrong MB, Greene MJ \& Robertson RP 1996 Effects of tacrolimus (FK506) on human insulin gene expression, insulin mRNA levels, and insulin secretion in HIT-T15 cells. Fournal of Clinical Investigation 98 2786-2794.

Ricordi C, Tzakis A, Alejandro R, Zeng YJ, Demetris AJ, Carroll P, Mintz DH \& Starzl TE 1991 In vivo effect of FK506 on human pancreatic islets. Transplantation 52 519-522.

Sato T, Inagaki A, Uchida K, Ueki T, Goto N, Matsuoka S, Katayama A, Haba T, Tominaga Y, Okajima Y, Ohta K, Suga H, Taguchi S, Kakiya S, Itatsu T, Kobayashi T \& Nakao A 2003 Diabetes mellitus after transplant: relationship to pretransplant glucose metabolism and tacrolimus or cyclosporine A-based therapy. Transplantation 76 1320-1326.

Shapiro AM, Lakey JR, Ryan EA, Korbutt GS, Toth E, Warnock GL, Kneteman NM \& Rajotte RV N 2000 Islet transplantation in seven patients with type 1 diabetes mellitus using a glucocorticoid-free immunosuppressive regimen. New England Fournal of Medicine 343 230-238.

Strasser S, Alejandro R, Shapiro ET, Ricordi C, Todo S \& Mintz DH 1992 Effect of FK506 on insulin secretion in normal dogs. Metabolism $4164-67$.

Sutherland DE, Gruessner RW, Dunn DL, Matas AJ, Humar A, Kandaswamy R, Mauer SM, Kennedy WR, Goetz FC, Robertson RP, Gruessner AC \& Najarian JS 2001 Lessons learned from more than 1000 pancreas transplants at a single institution. Annals of Surgery 233 463-501.

The Diabetes Control and Complications Trial Research Group 1998 Effect of intensive therapy on residual $\beta$-cell function in patients with type 1 diabetes in the diabetes control and complications trial: a randomized, controlled trial. Annals of Internal Medicine 128 517-523.

Todd JF, Wilding JP, Edwards CM, Khan FA, Ghatei MA \& Bloom SR 1997 Glucagon-like peptide-1 (GLP-1): a trial of treatment in non-insulin-dependent diabetes mellitus. European fournal of Clinical Investigation 27 533-536.

Uchida M, Hanai S, Uematsu N, Sawamoto K, Okano H, Miwa M \& Uchida K 2001 Genetic and functional analysis of PARP, a DNA strand break-binding enzyme. Mutation Research 477 89-96.

Zeng Y, Ricordi C, Lendoire J, Carroll PB, Alejandro R, Bereiter DR, Tzakis A \& Starzl TE 1993 The effect of prednisone on pancreatic islet autografts in dogs. Surgery 113 98-102.

Received 26 November 2004

Accepted 8 December 2004 